\title{
BMJ Global Health Impact of the global financial crisis on low birth weight in Portugal: a time-trend analysis
}

\author{
Musa Abubakar Kana, ${ }^{1,2}$ Sofia Correia, ${ }^{1}$ Barbara Peleteiro, ${ }^{1}$ Milton Severo, ${ }^{1,3}$ \\ Henrique Barros ${ }^{1,3}$
}

To cite: Kana MA, Correia S, Peleteiro B, et al. Impact of the global financial crisis on low birth weight in Portugal: a time-trend analysis. BMJ Global Health 2017;2: 000147 . doi:10.1136/bmjgh-2016000147

- Additional material is available. To view, please visit the journal (http://dx.doi.org/ 10.1136/bmjgh-2016000147)

Received 1 August 2016 Revised 14 October 2016 Accepted 24 October 2016

CrossMark

\footnotetext{
${ }^{1}$ Unidade de Investigação em Epidemiologia - Instituto de Saúde Pública da Universidade do Porto (EPIUnit, ISPUP), Porto, Portugal

${ }^{2}$ Department of Community Medicine, Faculty of Medicine, Kaduna State University, Kaduna, Nigeria ${ }^{3}$ Department of Clinical Epidemiology, Predictive Medicine and Public Health, University of Porto Medical School, Porto, Portugal
}

\section{Correspondence to} Dr Musa Abubakar Kana; musakana77@yahoo.com

\section{ABSTRACT}

Background: The 2007-2008 global financial crisis had adverse consequences on population health of affected European countries. Few contemporary studies have studied its effect on perinatal indicators with long-lasting influence on adult health. Therefore, in this study, we investigated the impact of the 2007-2008 global financial crisis on low birth weight (LBW) in Portugal.

Methods: Data on 2045155 singleton births of 19952014 were obtained from Statistics Portugal. Joinpoint regression analysis was performed to identify the years in which changes in LBW trends occurred, and to estimate the annual per cent changes (APC). LBW risk by time period expressed as prevalence ratios were computed using the Poisson regression. Contextual changes in sociodemographic and economic factors were provided by their trends.

Results: The joinpoint analysis identified 3 distinct periods (2 jointpoints) with different APC in LBW, corresponding to $1995-1999(\mathrm{APC}=4.4 ; 95 \% \mathrm{Cl} 3.2$ to 5.6), 2000-2006 (APC $=0.1 ; 95 \% \mathrm{Cl}-050$ to 0.7 ) and 2007-2014 (APC=1.6; 95\% Cl 1.2 to 2.0). For nonPortuguese, it was, respectively, 1995-1999 (APC=1.4; $95 \% \mathrm{Cl}-3.9$ to $7.0 \%$ ), 2000-2007 (APC $=-4.2 ; 95 \% \mathrm{Cl}$ -6.4 to -2.0 ) and $2008-2014$ (APC $=3.1 ; 95 \% \mathrm{Cl} 0.8$ to 5.5). Compared with 1995-1999, all specific maternal characteristics had a 10-15\% increase in LBW risk in 2000-2006 and a 20-25\% increase in 2007-2014, except among migrants, for which LBW risk remained lower than in 1995-1999 but increased after the crisis. The increasing LBW risk coincides with a deceleration in gross domestic product growth rate, reduction in health expenditure, social protection allocation on family/ children support and sickness.

Conclusions: The 2007-2008 global financial crisis was associated with a significant increase in LBW, particularly among infants of non-Portuguese mothers. We recommend strengthening social policies aimed at maternity protection for vulnerable mothers and health system maintenance of social equity in perinatal healthcare.

\section{BACKGROUND}

The 2007-2008 global financial crisis and sequel of economic recessions have resulted

\section{Key questions}

What is already known about this topic?

- The 2007-2008 global financial crisis and sequel of economic recessions have resulted in adverse consequences on population health of affected European countries.

- Perinatal health outcomes are among the exacerbated indicators during previous economic depressions.

- During economic crisis, there are changes in low birth weight risk factors like childbearing practices (eg, fertility postponement), nutrition, substance use patterns and access to healthcare.

\section{What are the new findings?}

- Portugal has been experiencing an upward but unequal trend in singleton low birth weight (LBW), described by three distinct periods that escalated after 2007-2008.

- The general increase in LBW risk during the past two decades in Portugal affects the different strata of the population variables, with the exception of nationality, with non-Portuguese women experiencing a decrease in LBW risk before the financial crisis.

- The increasing risk in LBW was concomitant with declining birth rates and with worst macroeconomic indicators, such as an increased unemployment and a deceleration in gross domestic product (GDP) growth rate. There was a reduction in government expenditure on health as a proportion of GDP, percentage expenditure of social protection on family/ children support and for sickness or healthcare.

in adverse consequences on population health of affected European countries. ${ }^{1}$ The economic downturn and its health impact has intensified the vulnerability of children as detected in Greece, where stillbirths and infant deaths increased from 2008 to 2010, and in Iceland, where the proportion of children born small-for-gestational age increased from $2.0 \%$ to $3.4 \% 6$ years after the banking collapse of October 2008. ${ }^{23}$ 


\section{Key questions}

\section{Recommendations for policy}

- The continuous monitoring of relevant risk factors, the quality assurance of the process and information on further indicators, as part of data routinely collected by the national birth registration system, are essential.

- There should be strengthening of social policies aimed at maternity protection for non-Portuguese, working and other vulnerable mothers.

- The health system should sustain its capacity to effectively maintain social equity in perinatal healthcare access, utilisation and quality

Birth weight is a major determinant of infant health and welfare that persists into later life. ${ }^{4}$ Taking as example cognitive outcomes, so intensively valued in our societies, and considering individual and contextual changes, low birth weight (LBW) long-term effects seem more marked when birth weight reflects mainly the contribution of socioeconomic pathways than where pathways relate mostly to biological risk factors. ${ }^{5}{ }^{6}$ Hence, fetal growth and birth weight have been employed to evaluate social policies as indicators of social inequalities sensitive to macroeconomic choices. ${ }^{7}$

LBW is among the adverse health outcomes exacerbated during previous economic depressions. ${ }^{8-10}$ Contextually, the heightening of LBW susceptibility during economic crisis denotes mediation through changes in the social profile of childbearing women and alterations in health behaviours. ${ }^{11}{ }^{12}$ Additionally, there may be environmental mediation, as health system responses are sensitive to reductions in funding of programmes or to general cost containment measures, which may constitute a constraint to healthcare access. ${ }^{8-}$

${ }^{10}$ Economic recession affects differently those at the top or at the bottom of the social hierarchy, emphasising the importance of individual protection in promoting health. ${ }^{12}$ Studies have recognised that during economic crisis, there are changes in childbearing practices, worsening nutrition, adoption of unhealthy coping strategies, modification of substance use patterns, decreased access to care and attention to health issues, as well as direct increases on stress. ${ }^{11} 12$ All these aspects can influence pregnancy outcomes, although the consequences pointing into different directions. Evidence about the impact of the current economic recession on health equity is still inconsistent and there is no such information available for the perinatal period. ${ }^{13}$

Although several contemporary studies have examined the impact of the recent financial crisis on specific health outcomes, less often they looked at perinatal indicators such as LBW that might have a long-lasting influence on adult health. ${ }^{14}$ There is paucity of research studies that consistently covered the link between health and key Portuguese socioeconomic problems. $^{15}$ Considering that the establishment of the universal healthcare and perinatal health services over the last 30 years has improved maternal and child health indicators in Portugal. ${ }^{16}{ }^{17}$ It is appropriate to investigate the impact of adverse social and macroeconomic conditions on birth weight by monitoring time-based and social patterns of LBW. ${ }^{9}{ }^{10}$ Therefore, we examined time trends in LBW during the past two decades in Portugal, researching the impact of the 2007-2008 global financial crisis and taking into consideration individual and contextual changes.

\section{METHODS}

\section{Data source}

Annual individual data concerning births and birth characteristics were obtained from Statistics PortugalInstituto Nacional de Estatística (INE) - for the period 1995-2014. Online supplementary data on migrations, crude birth rate, gross domestic product (GDP), unemployment and social security expenditure covering the period 1995-2014 were obtained from Statistics Portugal as well as the Ministry of Solidarity and Social Security.

\section{Study population}

The study population consisted of 2045155 singleton live births (mother-infant pairs) as recorded in the national birth registry. We excluded records for which birth weight $(\mathrm{n}=2976)$ and maternal nationality $(\mathrm{n}=109)$ were missing and those that, because of the possibility of error in data entry, were registered as $<500$ or $>6000 \mathrm{~g}$ $(\mathrm{n}=3007)$.

\section{Measures}

Birth weight is recorded in grams and corresponds to the first measure of weight obtained after birth, preferably during the first hour. In the national statistics, birth weight is also classified in $500 \mathrm{~g}$ categories, but for our analysis, we used only four: <1500, 1500-2499, 25003999 and $>3999$. Specifically, the main outcome variable considered in our analysis was the prevalence of LBW, defined as the proportion of singleton babies with birth weight $<2500 \mathrm{~g}$.

The duration of gestation, which is expressed in completed weeks, is calculated from the first day of the last normal menstrual period or based on ultrasound data. During the study period, there have been changes in the national policy regarding the record of gestational age, so for analysis, we considered the categories 22-31, $32-36,37-41$ and $>41$ and classified as preterm babies those with $<37$ completed weeks. The infant sex is recorded as male or female and the male to female ratio was calculated. The maternal age at birth was registered as a continuous variable, but for the purpose of this study was categorised as $\leq 19,20-34$ and $\geq 35$ years; maternal nationality referred to nationality at the moment of birth and, although recorded according to each individual country, was considered as Portuguese 
Figure 1 Trend in low birth weight rates among singleton births in Portugal 1995-2014.

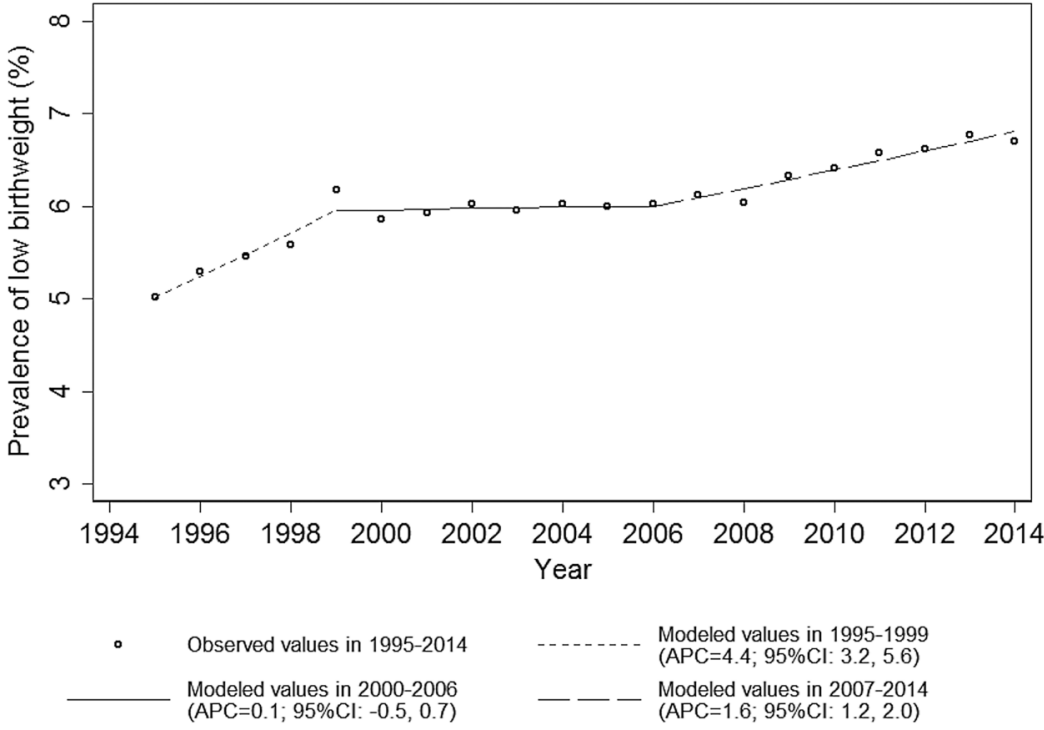

or other. Maternal or paternal employment status was recorded in 10 categories but for analysis classified as employed, unemployed or others (housewife, student, retired, incapacitated), and maternal education stratified as primary, secondary and tertiary.

\section{Statistical analysis}

To study trends in LBW and to estimate the annual percentage change, we employed a Poisson joinpoint regression model. ${ }^{18}$ The procedure models the counts in the numerator and denominator for each time period rather than the precalculated rates. In essence, this approach is equivalent to having data at the individual level with sample size equalling the number of individuals in the denominators of the rates instead of the number of time periods for which rates are available. A joinpoint represents a knot at which an important change in the temporal trend occurs; joinpoints are estimated iteratively and do not require the specification of an a priori hypothesis about the location of the knots to be tested. Weighted least squares to account for heteroscedasticity was included to fit a loglinear Poisson joinpoint regression model that was used. We also allowed for autocorrelation of the residuals to account for the fact that the observed rates are not independent. ${ }^{19}$

The Poisson regression analysis was performed using the Joinpoint Regression Program, V.4.2.0. ${ }^{20}$ The software fits the simplest joinpoint model that the data will allow using a series of permutation test. The estimated annual per cent change (APC) and their 95\% CIs were computed by fitting a regression line to the natural logarithm of the rates using calendar year as a regressor variable (ie, given $y=\ln$ (number of LBW) and $y=\ln$ (total of birth $+a+b x$ and $x=$ calendar year, the APC is estimated as $\left.100 \times\left(\mathrm{e}^{\mathrm{b}}-1\right)\right) \cdot{ }^{20}$ The final number of joinpoints was determined by comparing the best model with each number of change points using permutation tests, with a
Bonferroni correction to account for multiple hypothesis testing. ${ }^{19}$ The resulting graph for the best model had two joinpoints and it is a scatter plot of LBW rate from 1995 to 2014 (figure 1).

Additionally, $\chi^{2}$ test was used to compare maternal and infant characteristics at the three periods (19951999-reference period, 2000-2006 and 2007-2014). Considering that we are working with large samples, measures of effect size were preferred over significance tests to remove the dependence on sample size and the associated high probability of significant differences. We used Cohen's d effect sizes, which indicate the magnitude of differences between groups independent of sample size were values of $0.10,0.30$ and 0.50 or greater, which were considered small, moderate and large effect sizes, respectively. ${ }^{21}$

Log-binomial regression or log-Poisson regression was used to estimate the magnitude of the association between LBW and each variable considered (maternal nationality, age, education, employment status and infant sex), and expressed as prevalence ratio (PR) with corresponding $95 \%$ CIs.

The information on the contextual changes in sociodemographic and economic factors was provided by the trends in the net migration rate (difference of immigrants and emigrants in a period of time; a positive value represents more people entering the country than leaving it), crude birth rate (annual number of live births per 1000 population), GDP (monetary value of all the finished goods and services produced within a country's borders in a specific time period, measured in euros) and social security expenditure (comprises of budgetary allocation for social security with social purposes) from 1995 to 2014. The proportion of government expenditure on health over the study period was reported as budget execution per capita (euro-ratio) and budget execution as a percentage of GDP. The GDP is expressed 
as growth rate $(\%)$ and per capita based on purchasing power standards (PPS). When the comparison of GDPs in PPS is repeated for at least two periods, it is possible to infer the relative growth rates between the two periods. The unemployment rate represents unemployed persons (persons aged between 15 and 74 who during the reference period neither had a job nor were at work; were available for paid employment or self-employment; or had actively sought work) as a percentage of the civilian labour force, defined as the proportion of all persons aged 15 or over (14 or over until 1997) who, during the reference period, made up the available labour force for the production of economic goods and services.

Two approaches were used to study the relationship between maternal or infant characteristics and LBW time changes. First, the effect of each characteristic on LBW in time was assessed, fitting several models stratified by the characteristic of interest (adjusted for all the other variables) taking time as independent variable. Subsequently, we tested the effect of each characteristic on LBW taking into consideration that this effect can change in time. So, we fitted each model including the interaction between time and the characteristic under study (adjusted for the other variables). We used the likelihood ratio test to assess any significant interaction between the period and the characteristic (p-interaction).

SPSS V.21 (SPSS, Chicago, Illinois, USA) was used to calculate descriptive statistics and to perform the regression analyses.

\section{RESULTS}

\section{Trends in LBW in Portugal 1995-2014}

During the study period, the prevalence of LBW increased in singleton births from $5.0 \%$ in 1995 to $6.6 \%$ in 2014. The joinpoint analysis (figure 1) identified three distinct periods (2 jointpoints) corresponding to 1995-1999 (APC=4.4; 95\% CI 3.2 to 5.6), 2000-2006 $(\mathrm{APC}=0.1 ; 95 \% \mathrm{CI}-0.5,0.7)$ and 2007-2014 $(\mathrm{APC}=1.6$; 95\% CI 1.2 to 2.0). A distinct pattern was observed when looking separately to Portuguese born (figure 2) and migrant mothers (figure 3): for the babies of Portuguese mothers, the annual changes were positive though with only two different periods: 1995-1999 $(\mathrm{APC}=3.6 ; 95 \% \mathrm{CI} 2.1,5.0)$ and 2000-2014 (APC=1.0; $95 \%$ CI 0.8 to 1.2 ) while that in babies of mothers of other nationalities were three: 1995-1999 (APC=1.4; 95\% CI -3.9 to $7.0 \%$ ), 2000-2007 ( $\mathrm{APC}=-4.2 ; 95 \%$ CI -6.4 to -2.0$)$ and $2008-2014(\mathrm{APC}=3.1 ; 95 \%$ CI 0.8 to 5.5), with a significant increase after the crisis.

The annual number of singleton live births declined from 104636 in 1995 to 79918 in 2014. Table 1 presents the maternal and infant characteristics of the participants according to the three periods observed in the general sample. It is observed that the proportion of babies of native Portuguese mothers decreased from $97.8 \% \quad(1995-1999) \quad$ to $91.1 \% \quad(2007-2014)$.
Furthermore, the mean maternal age increased from $27.6 \pm 5.49$ years (1995-1999) to $30.1 \pm 5.63$ years (20072014). This followed a reduction in the proportion of teenage mothers from $6.9 \%(1995-1999)$ to $4.0 \%$ (2007-2014). Women with tertiary-level education increased from $13.0 \%$ to $32.0 \%$ between 1995-1999 and 2007-2014, while the proportion of unemployed mothers varied from $4.4 \%$ (1995-1999) to $13.0 \%$ (20072014). The effect size of the change by the Cohen criteria was small $(<0.10)$ for all characteristics except for maternal education that presented a moderate effect (0.21). However, all the comparisons of proportions and mean values were statistically significant at $\mathrm{p}<0.001$.

\section{Contextual changes of sociodemographic and economic indicators in Portugal 1995-2014}

In table 2, we present values for some relevant social, demographic and economic indices in Portugal, according to the three periods considered from 1995 to 2014. In 1995-1999, there was a positive net migration, but in subsequent years, a negative net migration was recorded particularly from 2008 onward, reflecting the large emigration of young Portuguese adults. On the contrary, the foreign population in the country has been on a steady rise with a remarkable increase in the period between 2008 and 2012, but began to reduce afterwards. The crude birth rate has been declining over the years with an important reduction, especially in the post-2008 period. The GDP growth rate $(\%)$ has been sliding during the observation period; 1995-1999 (4.2), 20002006 (1.5) and 2007-2014 (-1.0). The average GDP per capita (PPS) increased from 12872 in 1995-1999, to 17513 in 2000-2006 and to 20485 in 2007-2014. The unemployment rate increased in women from a maximum of 6.4 in the first period or 6.7 in the second to $16.0 \%$ after the financial crisis; a similar trend was seen for men among whom unemployment reached $16.4 \%$. The relative increase in GDP was higher between the first and second periods than between the second and third. Precisely, the proportion of government expenditure on health (budget execution as a percentage of GDP) increased between the initial (1995-1999; $3.9 \%)$ and intermediate $(2000-2006 ; 5.0 \%)$ periods but declined afterwards (2007-2014; 4.7\%). It was observed that the social security expenditure as percentage of GDP has steadily been increasing, especially in the period 2007-2014. This is reflected in the rise of the percentage expenditure of social benefit on unemployment. However, there was a reduction in the percentage expenditure of social benefit on family and children support and in sickness/maternity. During the study period, the crude death rate had a maximum of 106 per 10000 inhabitants from 1995 to 1999,104 in 2000 to 2006 and 102 in the period 2007 to 2014. During the same periods, infant death steadily decreased from 7.4 per 1000 live births in 1995 to reach 2.5 in 2010, than increasing to 3.4 in 2012 and reaching 2.9 in 2014. 
Figure 2 Trend in low birth weight rates among Portuguese singleton births in Portugal 1995-2014.

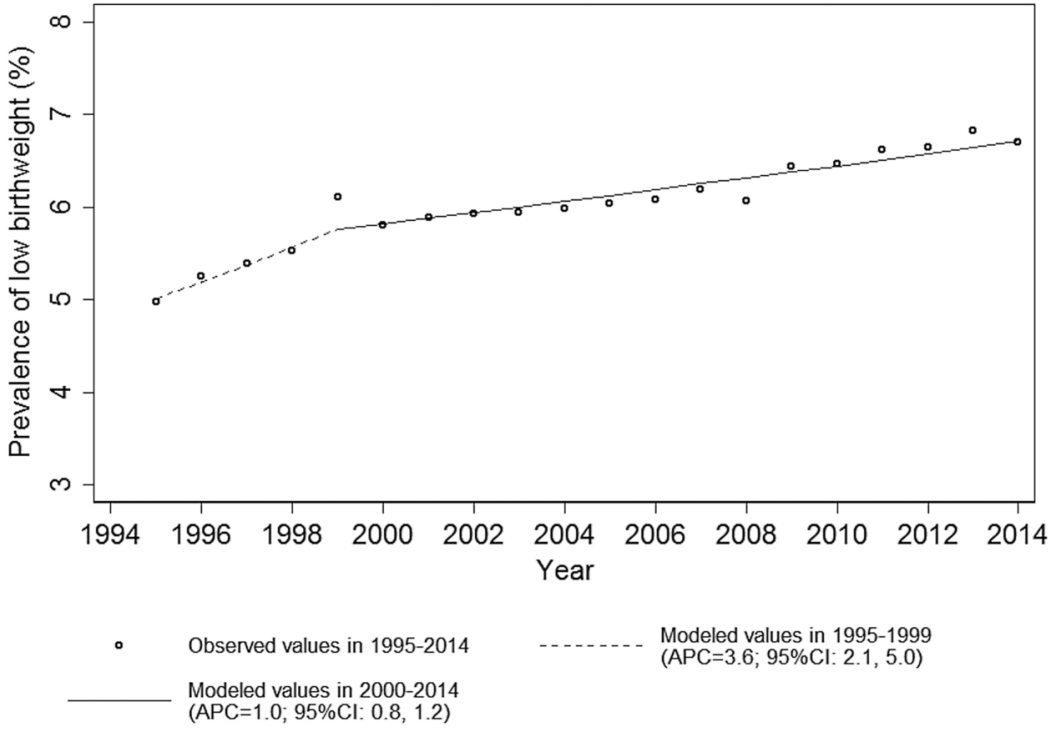

\section{Trend of LBW risk according to maternal and infant characteristics}

In a multivariate regression model, and considering 19951999 as the reference period, LBW risk increased, even after adjustment for maternal characteristics (table 3). It significantly increased in 2000-2006 ( $\mathrm{PR}=1.119 ; 95 \%$ CI 1.103 to 1.135$)$ and again in 2007-2014 ( $\mathrm{PR}=1.229 ; 95 \%$ CI 1.103 to 1.235). We found a significant interaction with all characteristics except with infant sex. However, the change in risk was different across strata of some infant and maternal characteristics. It increased with time in Portuguese women, while in the non-Portuguese, the risk decreased and was still lower after the crisis although less than in the intermediate period. While in women with a maternal age higher than 20, the LBW risk increased, in the younger group, there was a decrease during the observation period. The increase in LBW risk in primiparous women was similar to the multiparous. For the other characteristics, when compared with 1995-1999, LBW risk increased in 2000-2006 of about $10-15 \%$ and a more pronounced increase was observed in 2007-2014 (20-25\%).

\section{DISCUSSION}

Our findings indicate that between 1995 and 2014, Portugal has been experiencing an upward but unequal trend in singleton LBW, described by three distinct periods that escalated after 2007-2008. This development is concurrent with macroeconomic and sociodemographic transformations in the country. The broad interval of observation (1995-2014) enabled the detection of the transformation of LBW rate in babies of non-Portuguese mothers, which indicated a period of decline (2000-2006) and an upsurge (2007-2014). There was an overall increase in the proportion of LBW births, but its time-based distribution in babies of non-Portuguese mothers showed a gradient different from their Portuguese peers.
Figure 3 Low birth weight rates among non-Portuguese singleton births in Portugal 1995-2014.

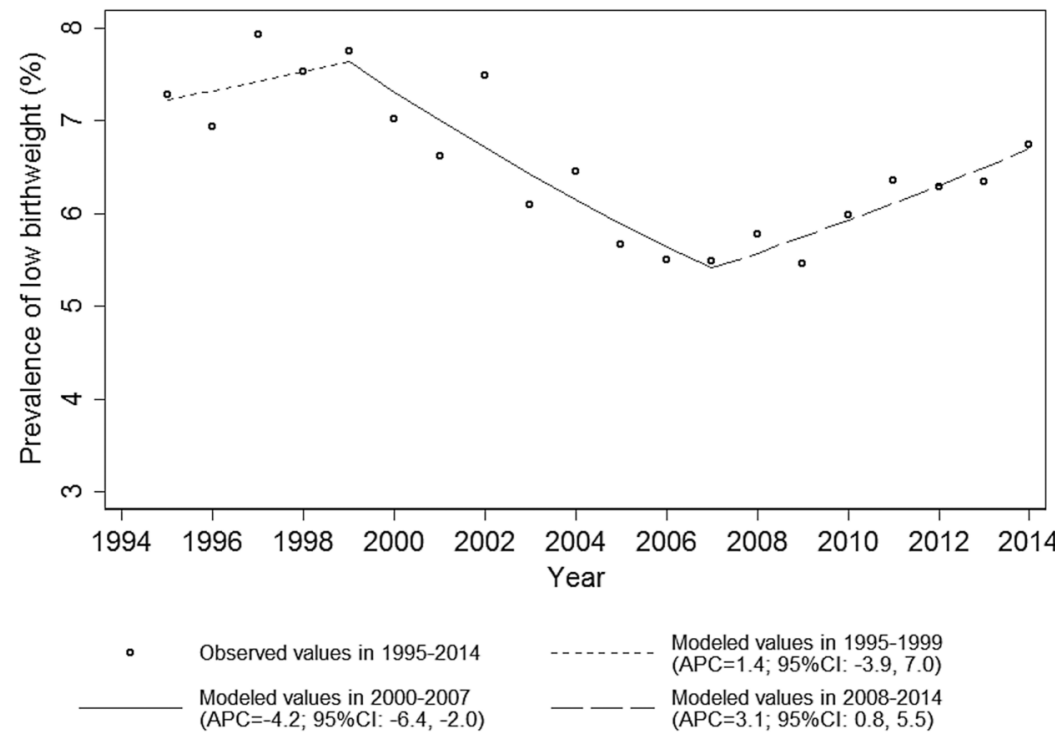


Table 1 Maternal and infant characteristics of singleton live births in Portugal, 1995-2014

\begin{tabular}{|c|c|c|c|c|}
\hline Variable & $\begin{array}{l}\text { 1995-1999 } \\
\text { n (\%) }\end{array}$ & $\begin{array}{l}\text { 2000-2006 } \\
\text { n (\%) }\end{array}$ & $\begin{array}{l}\text { 2007-2014 } \\
\text { n (\%) }\end{array}$ & Effect size (Cohen's d)* \\
\hline Total live births & $546032(26.7)$ & 762325 (37.3) & 736798 (36.0) & \\
\hline Portugal & $530430(97.1)$ & 709199 (93.0) & 663963 (90.1) & 0.11 \\
\hline Other country & $15602(2.9)$ & $53126(7.0)$ & 72835 (9.9) & \\
\hline Mean $( \pm)$ & $27.6(5.49)$ & $28.7(5.57)$ & $30.1(5.63)$ & \\
\hline$\leq 19$ & $37710(6.9)$ & $42906(5.6)$ & $29734(4.0)$ & 0.13 \\
\hline 20-34 & 447384 (81.9) & $605099(79.4)$ & $541738(73.5)$ & \\
\hline$\geq 35$ & $60938(11.2)$ & $114320(15.5)$ & $165326(22.4)$ & \\
\hline \multicolumn{5}{|l|}{ Maternal education } \\
\hline Primary & 375555 (68.8) & $420124(55.1)$ & 284270 (39.2) & 0.24 \\
\hline Secondary & $99277(18.2)$ & $179741(23.6)$ & $209131(28.8)$ & \\
\hline Tertiary & $71200(13.0)$ & $162220(21.3)$ & 232626 (32.0) & \\
\hline \multicolumn{5}{|l|}{ Maternal employment status } \\
\hline Employed & $342306(62.7)$ & $544958(71.5)$ & $511140(70.8)$ & 0.18 \\
\hline Unemployed & $24088(4.4)$ & $47093(6.2)$ & $93950(13.0)$ & \\
\hline Others & $179638(32.9)$ & 169635 (22.3) & $116416(16.1)$ & \\
\hline \multicolumn{5}{|l|}{ Paternal employment status } \\
\hline Male/female ratio & 1.07 & 1.07 & 1.05 & \\
\hline \multicolumn{5}{|l|}{ Gestational age at birth (weeks) } \\
\hline$<32$ (very preterm) & $4013(0.7)$ & $4871(0.6)$ & $5637(0.8)$ & 0.08 \\
\hline 32-36 (moderate-late preterm) & $26860(5.0)$ & $35716(4.7)$ & $42049(5.7)$ & \\
\hline 37-41 (term) & 497387 (92.3) & 691779 (90.9) & $679439(92.4)$ & \\
\hline >41 (post-term) & $10685(2.0)$ & $28743(3.8)$ & $8583(0.9)$ & \\
\hline \multicolumn{5}{|l|}{ Birth weight (g) } \\
\hline Mean $( \pm)$ & $3262.7(506.56)$ & $3229.3(498.66)$ & $3197.3(491.23)$ & \\
\hline$<1500$ & $3722(0.7)$ & $5150(0.7)$ & $5073(0.7)$ & 0.04 \\
\hline $1500-2499$ & $26366(4.8)$ & $40346(5.3)$ & $42268(5.7)$ & \\
\hline 2500-3999 & $482616(88.4)$ & 678757 (89.0) & $658970(89.4)$ & \\
\hline$>4000$ & $33328(6.1)$ & $38072(5.0)$ & $30487(4.1)$ & \\
\hline
\end{tabular}

*The $\mathrm{p}$ value for the comparison of the three periods using the $\chi^{2}$ test or analysis of variance, as appropriate, is $<0.001$ for all variables.

Generally, comparing with 1995-1999, a 10-15\% increase in LBW risk was observed in 2000-2006 for most maternal characteristics and a $20-25 \%$ increase was observed in 2007-2014. This argues in favour of a general increase in risk observed in the 21st century and not in specific groups of the population. ${ }^{22}$ Except the non-Portuguese women who experienced decreasing LBW risk that reversed after the crisis. For these women, the decreased risk reflects the overall decline in LBW prevalence in 2000-2006, although it increased again 
Table 2 Sociodemographic and economic indices in Portugal, 1995-2014

\begin{tabular}{|c|c|c|c|}
\hline Indicator & 1995-1999 & 2000-2006 & 2007-2014 \\
\hline Net migration rate & 42000 & 32300 & -14200 \\
\hline Proportion of females in foreign population (\%) & 41.8 & 44.8 & 49.8 \\
\hline Crude birth rate (per 1000 population) & 11.1 & 10.6 & 8.9 \\
\hline Crude death rate (per 1000 population) & 10.6 & 10.4 & 10.2 \\
\hline Infant death rate (per 1000 live births) & 7.4 & 5.5 & 3.6 \\
\hline GDP per capita (PPS millions, Euros) & 12872 & 17513 & 20485 \\
\hline GDP growth rate (\%) & 4.2 & 1.5 & -1.0 \\
\hline Government expenditure on health: budget execution per capita (Euro-ratio)* & 396.3 & 714.6 & 783.8 \\
\hline Government expenditure on health: budget execution as a \% of GDP* & 3.9 & 5.0 & 4.7 \\
\hline \multicolumn{4}{|l|}{ Unemployment rate (\%; highest value in the period) } \\
\hline Men & 6.4 & 6.7 & 16.0 \\
\hline Women & 8.2 & 8.9 & 16.4 \\
\hline Total social security expenditure as \% of GDP & 9.4 & 11.6 & 18.5 \\
\hline Total social security benefit (Euros, 1000s) & 8002079.0 & 13468539.0 & 20487826.3 \\
\hline$\%$ of total social security benefit for sickness/maternity & 6.9 & 5.1 & 4.1 \\
\hline Social security payment for sickness/maternity (1000s, Euros) & 549839.9 & 688814.0 & 830629.9 \\
\hline$\%$ of total social benefit for family/children (\%) & 5.5 & 4.8 & 4.4 \\
\hline Social security payment on family/children (1000s, Euros) & 439383.1 & 640032.3 & 895293.9 \\
\hline$\%$ of total social benefit for unemployment (\%) & 8.6 & 10.1 & 10.5 \\
\hline Social security payment for unemployment (1000s, Euros) & 691724.0 & 1364001.7 & 2148857.4 \\
\hline
\end{tabular}

Figures presented describe the mean value for the period except for crude and infant deaths as well as unemployment where the highest values were depicted.

Sources: Statistics Portugal (INE) and Instituto de Gestão Financeira da Segurança Social (IGFSS).

${ }^{*}$ Only data for 1995-2013 were officially documented.

†Social benefits/social security payments are transfers to households, in cash or in kind, intended to relieve them from the financial burden of a number of risks or needs, including: (a) sickness; (b) invalidity, disability; (c) occupational accident or disease; (d) old age; (e) survivors; (f) maternity; (g) family; (h) promotion of employment; (i) unemployment; (j) housing (k) education; (I) general neediness.

after the economic crisis (but not reaching the 19951999 levels). This pattern may represent differential selection to pregnancy, but also the heterogeneity within the group of migrant women and different migration flows over time, namely regarding the country of origin and women's social characteristics. Future research is fundamental to disentangle differences within migrants as well as between migrants and natives, and the impact of these differences on societies' health indicators, especially LBW.

The 2007-2008 global financial crisis triggered a negative impact on European economies that led to the introduction of strict economic austerity measures, as happened in Portugal. ${ }^{23}{ }^{24}$ In the Portuguese society, the impact of the crisis deepened after 2010, when a second phase of the financial and social crisis emerged, leading to more aggressive fiscal reforms that in turn worsened recession. ${ }^{25}$ The health policy response included an increase in employer and employee contribution rates either across the board or for specific population subgroups, increased or introduced user charges for health services, and medicines were subjected to increased out-of-pocket user charges, although the prices tend to decrease, accompanying an increase in the use of generics. ${ }^{25}$ This development had a negative impact on hospital care utilisation and no clear effect was evident on mortality figures. ${ }^{26}$ However, maternal and child health services remained free of charge even for non-documented migrants post-2008 when there was diminishing budgetary allocation for health.

Presently, our study has no documented precedence of demonstrating parallel LBW trends for migrant and native European women before and after the 2008 financial crisis. ${ }^{14}$ It is possible that the economic crisis affected them differently or they reacted differently to it. The plausible explanation for this variation may be in their contrasting LBW risk factors and the reactionary modification after recession. Possibly, there was a loss of the healthy immigrant effect in the context of a worse impact of the economic crisis on immigrants. ${ }^{27}$ It has been proposed that the interaction of fiscal austerity with economic shocks and weak social protection is what ultimately seems to escalate health and social crises in Europe. ${ }^{23}$ The vulnerable population including immigrants have been shown to bear greater burden of communicable diseases and there is disproportionate effect of austerity measures on migrant healthcare, even in countries that seem less affected by the economic 
Table 3 Trend of low birth weight risk according to maternal and infant characteristics: results of multivariate regression analysis

\begin{tabular}{|c|c|c|c|c|}
\hline & \multicolumn{3}{|c|}{ Prevalence ratio (PR) and $95 \% \mathrm{Cls}$} & \multirow[b]{3}{*}{ p interaction* } \\
\hline & & 2000-2006 & 2007-2014 & \\
\hline & 1995-1999 & PR $(95 \% \mathrm{Cl})$ & PR (95\% Cl) & \\
\hline Adjusted $†$ & 1 & $1.119(1.103$ to 1.135$)$ & $1.229(1.103$ to 1.235$)$ & \\
\hline \multicolumn{5}{|l|}{ Maternalł } \\
\hline \multicolumn{5}{|c|}{ Maternal age (years) $\ddagger$} \\
\hline$\leq 19$ & 1 & 0.958 (0.914 to 1.003$)$ & 0.937 (0.889 to 0.989$)$ & $<0.001$ \\
\hline $20-34$ & 1 & 1.151 (1.132 to 1.170$)$ & $1.269(1.248$ to 1.291$)$ & \\
\hline$\geq 35$ & 1 & $1.066(1.026$ to 1.106$)$ & $1.199(1.156$ to 1.244$)$ & \\
\hline \multicolumn{5}{|c|}{ Maternal education (years) $\ddagger$} \\
\hline Primary & 1 & $1.114(1.094$ to 1.133$)$ & 1.209 (1.186 to 1.232$)$ & 0.034 \\
\hline Secondary & 1 & $1.142(1.105$ to 1.181$)$ & $1.230(1.190$ to 1.271$)$ & \\
\hline Tertiary & 1 & $1.102(1.058$ to 1.147$)$ & $1.260(1.213$ to 1.310$)$ & \\
\hline \multicolumn{5}{|c|}{ Maternal employment statusł } \\
\hline Employed & 1 & $1.121(1.100$ to 1.141$)$ & $1.248(1.225$ to 1.272$)$ & $<0.001$ \\
\hline Unemployed & 1 & $1.131(1.066$ to 1.200$)$ & $1.209(1.144$ to 1.278$)$ & \\
\hline Others & 1 & $1.122(1.094$ to 1.150$)$ & $1.190(1.157$ to 1.224$)$ & \\
\hline \multicolumn{5}{|l|}{ Infant sex $\ddagger$} \\
\hline
\end{tabular}

${ }^{*} p$ Value for the comparison of a model with and without the interaction term between the variable and time.

†Adjusted for maternal nationality, maternal age (years), parity, maternal education, maternal employment status and infant sex. $\ddagger$ Adjusted for all other variables and an interaction term between the variable and time.

downturn. $^{28} 29$ On a wider scale, the economic crisis has more effect on 'crisis-sensitive' measures of ill-health, particularly in the longer term. Mainly, it has been observed that the effects of this economic depression were more marked in nations with lower levels of social protection, compared with those with higher levels. ${ }^{1}$ In Portugal, there has been an increase in the total expenditure for social protection as a response to the recession. But concomitant percentage expenditure of social protection on family and healthcare has been reduced over the crisis period.

Certainly, there are recognised sociodemographic and biological factors that mediate variations in $\mathrm{LBW}^{7} \mathrm{We}$ observed an increasing maternal age and LBW risk among older mothers in Portugal during the economic recession (2007-2014). Although there is controversy as to whether age is an independent determinant of intrauterine growth or gestational duration, LBW and preterm births are generally more common after 35 years of age. ${ }^{7}{ }^{30}$ Assisted reproductive technologies are also more frequently present among older women, particularly primiparae, as it were the case in Portugal, and it is also more frequently associated with twins and adverse pregnancy outcomes. ${ }^{7} 3132$ We partially avoided such effect by limiting our study to singleton births.

Since the 1970 s, fertility trends in developed countries have been dominated by the shift in childbearing to ever-later ages. ${ }^{33}$ This shift, often described as fertility postponement, may be partly or largely driven by period factors, such as economic ups and downs or sudden changes in the labour market and government policies. $^{33}$ The economic uncertainty coupled with waning social support for families during the recession can contribute to magnifying childbirth postponement. ${ }^{34}$ Some recent studies expound that the association of economic decline (current and previous) and obstetric outcomes (eg, LBW) is intermediated by direct and indirect modification in fertility behaviour like childbearing postponement. $^{31} 3435$ Given the socioeconomic advantages (higher education, employed and higher income) of those who postpone having children, some authors have argued that the disadvantage experienced by certain groups in the context of a heterogeneous population, as in the USA, would be reduced if 
they postponed their births to improve their education and income. ${ }^{36}$ It is known that childbearing postponement and child outcome is a complex and varied relationship, especially in heterogeneous populations, but that is not the case in Portugal, where annual registry of births accounted by more than $90 \%$ native Portuguese mothers. ${ }^{35} 36$

Fundamentally, socioeconomic circumstance of families provides an alternative causal approach for explaining the time-based variation of LBW. The proxy variables we used to tackle socioeconomic circumstances comprised maternal employment and education. Indeed, the economic crisis may result in adverse effect on population health consequent to heightened unemployment. ${ }^{37}$ But the role of education and employment in the association between economic crisis and LBW is not fully understood. Nevertheless, it is known that increased total months worked during pregnancy, total daily working hours and time mothers spent standing up are significant aetiological factors of intrauterine growth retardation. ${ }^{38}$ These are critical practices that are associated with an employed mother. In this study, we noted that a tertiary educated and employed mother had a greater LBW risk during the economic contraction. Contrary to our result, another study reports that women with higher education had lower risk of LBW after the onset of the economic crisis in Andalusia, Spain; an area accounting for $19 \%$ of births in the country. ${ }^{39}$ The variation in maternal social characteristics, health behaviours and health system may explain the differences in maternal educational gradient and LBW relationship for Portugal and Spain during the recession.

The consequences of the economic crisis on population health occur suddenly or gradually. ${ }^{23}$ This study showed that the alteration in LBW trend started even before the implementation of austerity measures later in the recession. This finding reaffirms that the impact of the economic crisis on LBW is mediated by the synergistic effect of multiple factors. A causal perspective that may explain the sudden change in the course of LBW trend infers that maternal exposure to stressful life events like economic crisis prior to conception or during pregnancy influences infant birth weight. ${ }^{40-44}$ During the recent economic crisis, high levels of antenatal stress, anxiety and depressive symptoms have been documented among low-risk pregnant women, in an economically impacted area of Ireland. ${ }^{43}$ Tragic events are also known to trigger communal bereavement, which lead to perinatal health outcome changes as illustrated by the significant surge in very LBW the months following the Swedish Prime minister Olof Palme's murder in 1986 or the sinking of a ferry in Estonia in $1994 .^{45}$

The articulation of a comprehensive causal framework is important for a detailed investigation of the aetiological process of the impact of economic crisis on LBW. This would have augmented our explanation of LBW trend and its intermediary factors. Unfortunately, the Portuguese birth registry system we based our analysis does not collect information on LBW risk factors, such as maternal substance abuse, prenatal care and morbidity. ${ }^{46}$ Maternal smoking has been identified as the most important and modifiable risk factor for LBW in developed countries. But there is an indirect evidence of a rise in smoking among women of childbearing age in Portugal that preceded the economic crisis. ${ }^{47}$ Thus, we expect that the independent role of this factor on LBW might add complexity to the estimated association during the study period.

The initiation year of this study was selected to cover a sufficiently long period so that sustainable trends could be accommodated. Hence, the major strengths of our study were the large sample size and extensive observation time that was sufficient to our hypothesis. The duration had allowed a satisfactorily lengthy interval that enabled simultaneous observation of time-based variation of LBW and part of its potential mediators (maternal characteristics). The Poisson regression analysis we employed has the advantage of accounting for the fluctuation across time and the variability at each time point. In addition, it is useful in detecting abrupt changes and describing shifting time trends that are applicable to our aim of detecting variation, particularly due to the economic recession without forcing any prejudgement.

The prolongation of the economic crisis portends a threat to perinatal healthcare, especially for non-Portuguese and vulnerable mothers with increased LBW risks; older ( $>35$ years), tertiary educated and employed. Therefore, it is necessary to improve labour conditions of pregnant mothers and minimise other stressful circumstances. ${ }^{38}$ It is discernible that in times of financial hardship, there is a temptation to revise the universal health policy and cut services for minority populations. ${ }^{28}$ Accordingly, the health system should effectively maintain social equity in perinatal healthcare access and outcomes. It is noteworthy that in a developed country setting, non-resident women without healthcare coverage are more susceptible to adverse perinatal outcome than their native counterparts. ${ }^{48}$ Even though, the universal healthcare and perinatal healthcare system instituted over three decades contributed to the mitigation of adverse perinatal outcomes for all categories of mothers in Portugal. ${ }^{16}{ }^{17}$ The continuous reduction in public health expenditure constitute a detriment to assuring access, equity and quality of perinatal care because health systems require predictable sources of revenue to plan in a sustainable way. ${ }^{25}$

\section{CONCLUSIONS AND POLICY IMPLICATIONS}

The 2007-2008 global financial crisis is associated with increased LBW occurrence in Portugal that is more evident in infants of non-Portuguese mothers. It is not possible to conclusively propose a mediatory mechanism 
on how the financial crisis resulted in a higher rate of LBW and to what extent the resilience of available health and social responses buffered the effect of adverse individual or social level exposures. Further research will be required to improve the understanding of the role of particular factors, such as maternal nationality, fertility behaviour and the amplification of late maternity, substance abuse and mental stress, in the variation of LBW during periods of economic depression. The continuous monitoring of relevant risk factors, the quality assurance of the process and information on further indicators, as part of data routinely collected by the national birth registration system, are essential. Finally, there should be strengthening of social policies aimed at maternity protection for non-Portuguese, working and other vulnerable mothers. The health system should sustain its capacity to effectively maintain social equity in perinatal healthcare access, utilisation and quality.

\section{Handling editor Sanni Yaya.}

Acknowledgements Statistics Portugal (INE) is appreciated for providing the database used for the analysis. This study was funded by FEDER through the Operational Programme Competitiveness and Internationalization and national funding from the Foundation for Science and Technology - FCT (Portuguese Ministry of Science, Technology and Higher Education) (POCl-01-0145FEDER-016874), under the project "Migrants and Perinatal Health: Barriers, Incentives and Outcomes (baMBIN0)" (Ref. FCT PTDC/DTP-SAP/6384/2014) and the Unidade de Investigação em Epidemiologia - Instituto de Saúde Pública da Universidade do Porto (EPIUnit) (POCI-01-0145-FEDER-006862; Ref. UID/DTP/04750/2013).

Contributors MAK and HB conceived and designed the study and analysis. $\mathrm{SC}, \mathrm{MAK}$ and BP collected data and prepared the data sets. MAK, BP, MS and $\mathrm{HB}$ analysed the data. MAK drafted the manuscript. HB reviewed, edited and revised the manuscript as well as supervised all the processes. All authors interpreted data and revised the manuscript critically for intellectual content. Finally, all the authors read and approved the final version.

Competing interests None declared.

Provenance and peer review Not commissioned; externally peer reviewed.

Data sharing statement No additional data are available.

Open Access This is an Open Access article distributed in accordance with the Creative Commons Attribution Non Commercial (CC BY-NC 4.0) license, which permits others to distribute, remix, adapt, build upon this work noncommercially, and license their derivative works on different terms, provided the original work is properly cited and the use is non-commercial. See: http:// creativecommons.org/licenses/by-nc/4.0/

\section{REFERENCES}

1. Toffolutti V, Suhrcke M. Assessing the short term health impact of the Great Recession in the European Union: a cross-country panel analysis. Prev Med 2014;64:54-62.

2. Gunnlaugsson $\mathrm{G}$. Child health in Iceland before and after the economic collapse in 2008. Arch Dis Child 2016;101:489-96.

3. Michas G, Varytimiadi A, Chasiotis I, et al. Maternal and child mortality in Greece. Lancet 2014;383:691-2.

4. Malin GL, Morris RK, Riley R, et al. When is birthweight at term abnormally low? A systematic review and meta-analysis of the association and predictive ability of current birthweight standards for neonatal outcomes. BJOG 2014;121:515-26.

5. Kim D, Saada A. The social determinants of infant mortality and birth outcomes in Western developed nations: a cross-country systematic review. Int J Environ Res Public Health 2013;10:2296-335.
6. Hair NL, Hanson JL, Wolfe BL, et al. Association of child poverty, brain development, and academic achievement. JAMA Pediatr 2015;169:822-9.

7. Kramer MS. Determinants of low birth weight: methodological assessment and meta-analysis. Bull World Health Organ 1987;65:663-737

8. Blumenshine P, Egerter S, Barclay CJ, et al. Socioeconomic disparities in adverse birth outcomes: a systematic review. Am J Prev Med 2010;39:263-72.

9. De Vos P, Garcia-Farinas A, Alvarez-Perez A, et al. Public health services, an essential determinant of health during crisis. Lessons from Cuba, 1989-2000. Trop Med Int Health 2012;17:469-79.

10. Carlson E, Tsvetarsky S. Birthweight and infant mortality in Bulgaria's transition crisis. Paediatr Perinat Epidemiol 2000;14:159-62.

11. Zilko CE. Economic contraction and birth outcomes: an integrative review. Hum Reprod Update 2010;16:445-58.

12. Ruhm CJ. Healthy living in hard times. $J$ Health Econ 2005;24:341-63.

13. Bacigalupe A, Escolar-Pujolar A. The impact of economic crises on social inequalities in health: what do we know so far? Int $J$ Equity Health 2014:13:52.

14. Rajmil L, Fernandez de Sanmamed MJ, Choonara I, et al. Impact of the 2008 economic and financial crisis on child health: a systematic review. Int $J$ Environ Res Public Health 2014;11:6528-46.

15. Campos-Matos I, Russo G, Perelman J. Connecting the dots on health inequalities - a systematic review on the social determinants of health in Portugal. Int J Equity Health 2016;15:26.

16. Neto MT. Perinatal care in Portugal: effects of 15 years of a regionalized system. Acta Paediatr 2006;95:1349-52.

17. Barros $\mathrm{H}$, Tavares $\mathrm{M}$, Rodrigues $\mathrm{T}$. Role of prenatal care in preterm birth and low birthweight in Portugal. J Public Health Med 1996;18:321-8.

18. Kuhn L, Davidson LL, Durkin MS. Use of Poisson regression and time series analysis for detecting changes over time in rates of child injury following a prevention program. Am J Epidemiol 1994;140:943-55

19. Kim HJ, Fay MP, Feuer EJ, et al. Permutation tests for joinpoint regression with applications to cancer rates. Stat Med 2000;19:335-51.

20. Joinpoint Regression Program. Version 4.1.1. Statistical Methodology and Applications Branch, Surveillance Research Program. National Cancer Institute, 2014.

21. Cohen J. A power primer. Psychol Bull 1992;112:155-9.

22. Fuster V, Santos C. Determinants of birth weight in Portugal: 1988 to 2011. Anthropol Anz 2016;73:33-43.

23. Karanikolos M, Mladovsky P, Cylus J, et al. Financial crisis austerity, and health in Europe. Lancet 2013;381:1323-31.

24. McKee M, Karanikolos M, Belcher P, et al. Austerity: a failed experiment on the people of Europe. Clin Med (Lond) 2012;12:346-50.

25. Mladovsky $\mathrm{P}$, Cylus J, Karanikolos M, et al. Health policy responses to the financial crisis in Europe. World Health Organization and European Observatory on Health Systems and Policies, 2012.

26. Perelman J, Felix S, Santana R. The Great Recession in Portugal: impact on hospital care use. Health Policy 2015;119:307-15.

27. Gotsens M, Malmusi D, Villarroel N, et al. Health inequality between immigrants and natives in Spain: the loss of the healthy immigrant effect in times of economic crisis. Eur J Public Health 2015;25:923-9.

28. O'Donnell C, Burns N, Dowrick C, et al. Health-care access for migrants in Europe. Lancet 2013;382:393.

29. Suhrcke M, Stuckler D, Suk JE, et al. The impact of economic crises on communicable disease transmission and control: a systematic review of the evidence. PLOS ONE 2011;6:e20724.

30. Newburn-Cook CV, Onyskiw JE. Is older maternal age a risk factor for preterm birth and fetal growth restriction? A systematic review. Health Care Women Int 2005;26:852-75.

31. Schmidt L, Sobotka T, Bentzen JG, et al. Demographic and medical consequences of the postponement of parenthood. Hum Reprod Update 2012;18:29-43.

32. Restrepo-Mendez MC, Lawlor DA, Horta BL, et al. The association of maternal age with birthweight and gestational age: a cross-cohort comparison. Paediatr Perinat Epidemiol 2015;29:31-40.

33. Sobotka $\mathrm{T}$, Lesthaeghe $\mathrm{R}$, Frejka $\mathrm{T}$, et al. Postponement and recuperation in cohort fertility: Austria, Germany and Switzerland in a European context. Comp Popul Stud 2011;36:417-52.

34. Sobotka T, Skirbekk V, Philipov D. Economic recession and fertility in the developed world. Popul Dev Rev 2011;37:267-306. 
35. Neels K, Theunynck Z, Wood J. Economic recession and first births in Europe: recession-induced postponement and recuperation of fertility in 14 European countries between 1970 and 2005. Int J Public Health 2013;58:43-55.

36. Goisis A, Sigle-Rushton W. Childbearing postponement and child well-being: a complex and varied relationship? Demography 2014:51:1821-41.

37. Stuckler D, Basu S, Suhrcke M, et al. The public health effect of economic crises and alternative policy responses in Europe: an empirical analysis. Lancet 2009;374:315-23.

38. Romo A, Carceller R, Tobajas J. Intrauterine growth retardation (IUGR): epidemiology and etiology. Pediatr Endocrinol Rev 2009;6 (Suppl 3):332-6.

39. Juarez S, Revuelta-Eugercios BA, Ramiro-Farinas D, et al. Materna education and perinatal outcomes among Spanish women residing in southern Spain (2001-2011). Matern Child Health J 2014;18:1814-22.

40. Witt WP, Cheng ER, Wisk LE, et al. Maternal stressful life events prior to conception and the impact on infant birth weight in the United States. Am J Public Health 2014;104(Suppl 1):S81-9.

41. Staneva A, Bogossian F, Pritchard M, et al. The effects of maternal depression, anxiety, and perceived stress during pregnancy on preterm birth: a systematic review. Women Birth 2015;28:179-93.

42. Zhao Y, Kershaw T, Ettinger AS, et al. Association between life event stressors and low birth weight in African American and White populations: findings from the 2007 and 2010 Los Angeles Mommy and Baby (LAMB) surveys. Matern Child Health $J$ 2015;19:2195-205

43. Carolan-Olah M, Barry M. Antenatal stress: an Irish case study. Midwifery 2014;30:310-16.

44. Bharadwaj P, Vogl TS. Crisis and human biology. The Oxford Handbook of Economics and Human Biology, 2016:52.

45. Catalano R, Hartig T. Communal bereavement and the incidence of very low birthweight in Sweden. J Health Soc Behav 2001;42:333-41.

46. Zeitlin J, Wildman K, Breart G, et al. PERISTAT: indicators for monitoring and evaluating perinatal health in Europe. Eur J Public Health 2003;13(3 Suppl):29-37.

47. Carreira H, Pereira M, Azevedo A, et al. Trends in the prevalence of smoking in Portugal: a systematic review. BMC Public Health 2012;12:958.

48. Maslovitz S, Kupferminc MJ, Lessing JB, et al. Perinatal outcome among non-residents in Israel. Isr Med Assoc J 2005;7:315-19. 